\title{
PRODUCTIVE LANGUAGE USE WITH IT'S ENGLISH
}

\author{
J. G. M. Jaspers, G. KanselaAR* and W. A. M. KoK \\ Department of Educational Sciences, University of Utrecht, Heidelberglaan 2, \\ 3584 CS Utrecht, The Netherlands
}

\begin{abstract}
Based on the results of a study in 1989, a new Computer-Assisted Instruction program for foreign language teaching of English has been developed. Main features of this program are the communicative approach, a 70,000 word dictionary, sound and a syntactic parser.

An evaluation study was carried out to explore the possibilities of this program. Four groups of eight students from two schools using different methods for tcaching English used the program for 8 weeks. The aim of this study was to gain insight into the usage of the program, by the students and the learning results. First results indicate that pupils who worked with the more communicative methods for teaching English made greater progress in acquiring vocabulary than those taught more traditionally.
\end{abstract}

\section{THEORETICAL BACKGROUNDS IN THE DEVELOPMENT OF IT'S ENGLISH}

To a large extent foreign language teaching is directed towards communicative goals. Socio-cultural developments (mass media, holidays abroad, etc.), scientific developments in teaching methodology, the use of new media, linguistics and psycholinguistics have led to a more functional approach to foreign language teaching. The traditional grammar-translation method, in which vocabulary was learned mostly by memorizing language 1 , language 2 pairs and in which grammar was taught as a system of rules, did not directly lead to oral fluency. In developing the CAI program we chose the communicative approach to foreign language teaching. In this approach language is viewed as an instrument of human behaviour. The behavioral situation is carefully selected in teaching. The linguistic context, the situation, speakers' roles and types of texts are all taken into careful consideration in the communicative approach. Linguistic function is secn as morc important than linguistic form. The structuring of the learning materials is first and foremost determined by communicative needs.

When designing the learning materials for the CAI programme we used Neuner's typology as a starting point for the construction of exercises. The three types of exercises in the program, including receptive (cloze texts) and productive (free sentence input) exercises can be placed on this continuum.

\section{AIMS AND ASSUMPTIONS}

The aim of the project is to create a computer-assisted learning environment for communicative foreign language teaching[1]. This form of foreign language teaching is oriented towards an active and passive command of a foreign language in everyday situations. It avoids translation as the only or the most important means of conveying meaning. Vocabulary is acquired on the basis of context-specific sentences and meanings in the foreign language, to ensure the devclopment of a language system that is separate from the learner's native language. In addition to the syntactic and morphological characteristics of words, their pronunciation is of great importance, as is sentence intonation. The sound of a new word is a basic element in assigning meaning to that word, so a great number of words and sentences were stored on CD-ROM. The aim of communicative language teaching is mainly achieved by having students use the non-native language productively.

The program IT'S ENGLISH is primarily aimed at teaching vocabulary. However, as an intelligent tutorial system it is also eminently usable in the teaching of writing. In the following

*To whom all correspondence should be addressed. 
sections the program itself will be described, followed by a report on research with the program that was carried out in two schools. In this research only the receptive and reproductive exercises were used in class. For the free-writing exercise the parser had to be used, which works under Windows 386 in Prolog 2. This was not possible using the XT-computers available in the schools.

\section{DESCRIPTION OF THE IT'S ENGLISH PROGRAM}

A computer program that supports the above basic aims and assumptions should enable the user to retrieve semantic definitions and context sentences in English, as well as synonyms, autonyms, pronunciation and the syntactic and morphological properties of words. In addition such a program should be capable of evaluating the user's use of language to enable him or her to apply the vocabulary in productive and reproductive exercises. To achieve all this the program consists of several components:

(i) an automatic sentence parser which checks random language input for syntactic, orthographic or inflectional correctness;

(ii) a CD-ROM database, which contains definitions and context sentences in everyday English, as well as the grammatical properties and synonyms and autonyms of over 70,000 words;

(iii) a CD-ROM database with the digitized pronunciation of 5000 words, 1200 context sentences and a number of texts for the presentation of phonetic word representations and English intonation;

(iv) a CD-ROM database with texts from the Notting Hill Gate textbook by Malmberg (third grade);

(v) an exercise generator, which generates exercises for passive, active and reproductive language use;

(vi) a feedback-generator, which uses the domain-input of the parser to reveal and remedy learner errors in (re)productive exercises.

The Collins COBUILD English Language Dictionary [2] was chosen as a basis for the lexical CD-ROM database. This dictionary meets the following requirements. It was compiled for non-native learners of English. Each word is accompanied by a semantic definition in simple English, and a number of authentic, explanatory citations. In addition, each word meaning is accompanied by systematic and moderately detailed grammatical information, for use by a parser This direct connection between grammatical information and the semantic section makes the meaning of every word that is recognized by the parser instantly available for retrieval, as well as a number of context sentences and other relevant information such as synonyms, autonyms and superordinate terms. One inherent restriction in the application is that the parser's power, that is, the number of English structures that can be automatically parsed, is limited by the grammatical information available in COBUILD. An important advantage of using such an extensive dictionary is the availability of information on nearly all English words. In previous studies [3] we found that in productive exercises with limited dictionaries ( 2000 words) pupils often use words that are not in the selected subset of English.

\section{CD-ROM AS A STORAGE MEDIUM}

Until recently it had not been possible in computer-aided education to devote much attention to foreign-language pronunciation, in view of the large amounts of external memory involved. To a large extent the arrival of $\mathrm{CD}-\mathrm{ROM}$ has removed this restriction. In this project CD-ROM was used as a storage medium both for digitized pronunciation and the lexical database based on Collins COBUILD English Language Dictionary. The final choice of the Extended Architecture (XA) standard for the CD-ROM in our project is exclusively related to the audio-component. 
The most important considerations in the choice of the XA-standard for the audio-component were the following:

(1) The sound-quality had to be optimal. The absence in speech of higher sound frequencies $(3500-11,000 \mathrm{~Hz})$ makes it very difficult to distinguish the pronunciations of certain words in English, where more or less subtle sound differences signal differences in meaning.

(2) In the acquisition of good foreign-language pronunciation, it is important for learners that the phonetic representations of words should be presented not only in isolation but also in sentence contexts. The learner should experience the pronunciation of words as being connected with and influenced by their contextual position as well as by the intonation of the sentence. The XA-standard is unique in meeting these requirements. It allows for the storage and reproduction of audio-information at three high-quality levels. The total capacity of the middle- and high-levels for separate words (up to $12,000 \mathrm{~Hz}$ ) is $8 \mathrm{~h}$. At the lowest-quality level for context sentences and texts (frequencies up to $8000 \mathrm{~Hz}$ ) the system can produce a considerable quantity of speech of very good quality, meeting requirements more than adequately.

\section{PROGRAM EXERCISES}

\section{The exercise generator}

The generator is capable of generating different types of exercises based on texts stored in the databases. Exercises have been developed for the program, which range from reading exercises to free writing. These exercises follow a route from receptive via reproductive to productive language use, and may be completed in a teacher- or learner-determined sequence. Three types of exercises have been developed so far in the making of the program. These are prototypical of the type of application that is possible with such programs. In developing these exercises we have followed Neuner [4], who distinguishes three main phases in an exercise sequence that leads to communicative language use. With the aid of the newly-developed parser, adding exercises in more elaborate versions of the program is a relatively simple matter.

(A) Reading texts (receptive use). A fragment of a story is selected by the student or teacher from the text database. Learners are free to retrieve a definition of each text-word in English, or the context sentence that accompanies each word. On the basis of information in the property list, new words in the text may be presented in inverse video. As soon as a text has appeared on the screen, an instruction may be given to search for the word in the lexical database. Definitions and contexts may be retrieved or presented separately. Apart from these possibilities the learner can call up the pronunciation of 5000 words and 1200 context sentences. Where appropriate synonyms, antonyms or superordinate terms can also be called up. It is also possible for the teacher to mark a word in advance to indicate that the learner should call up information about that word later. In this process word-specific feedback can be provided by the teacher.

(B) Texts with blanks (reproductive use). In the creation of texts with blanks, one or more properties of a word, all of which are recorded in the parser's property-list, may serve as a criterion for the omission of that word from the exercise, or for its inclusion in it. For example, texts could be created without any prepositions or adjectives. The decision to leave out all nouns, verbs, prepositions or adjectives can be taken by the teacher or the learner. Sentence constituents such as verb phrases can also be left out. This type of filling-in exercise is clearly superior to the cloze-tests of current prevalence, in which only every $n$th word may be omitted. Since the parser can be put into operation in the analysis of the learners' answers, feedback can be provided which is aimed at various kinds of errors. This makes IT'S ENGLISH different from traditional programs, in which every erroneous answer, plus the accompanying feedback, has to be anticipated and dealt with. The type of feedback that is provided by IT'S ENGLISH for filling-in exercises can be of the following kind: the typed-in answer is synonymous with a superordinate concept; the word class is correct but the actual word is not; information about possible typing errors; information about conjugation and other grammatical characteristics. It is also possible to provide help by giving a context sentence provided by the dictionary from which the target word has also been omitted. This turns out to be particularly informative. 
(C) Random text-input (productive use). This type of exercise allows the learner to type in a story. The parser checks each sentence for grammatical correctness. When an error occurs a feedback message is generated and the learner is given an opportunity to correct the error. The final story is stored in the text database, and can thus serve as a basis for new exercises. This enables learners, among other things, to complete fill-in exercises for each other. All the help options based on the dictionary that are available for the receptive exercises are similarly available for this type of productive exercise. The structure of a sentence can be made visible in tree-form on the screen. This possibility of random language input has one drawback: it makes great demands on the speed and capacity of the computer. However, in our opinion the program is uniquely valuable at present precisely because of its capacity for processing random input, with feedback about the grammaticality of input-sentences.

In the teaching of writing various aspects of writing practice can be dealt with, such as planning and organization, formulation and revision. The program offers help in formulation at sentence level. A particularly powerful aid is the ability to call up context sentences for a particular word in order to examine its use in frequently occurring contexts.

\section{Learner registration}

The program stores information concerning the words that each learner has studied up to a given moment, the help that has been requested and the answers to the exercises that have been given. These data can be scrutinized by the teacher.

\section{The feedback generator}

This is the part of the program that provides correct and appropriate forms of feedback for input-errors identified by the parser. In case of multiple syntactic errors in one sentence the program confines itself to signalling that the sentence is wrong. For an erroneous sentence such as 'He walk in the street', the program can indicate that the third-person singular ending is missing in the verb, but for many other errors the Prolog backtracking mechanism makes it difficult to establish what error occurred where. The option of calling up context sentences for critical words in the erroneous sentence can, however, in itself provide a great deal of information concerning the correct use of the relevant words.

\section{Exercise development}

The system applications allow learners as well as teachers to enter random texts for the development of exercises. For example, a teacher could in principle enter a text for later use by the learner to develop exercises. There are two entry-checks. The first one tests whether the word with the desired grammatical properties is present in the computer lexicon. The second check tests whether the parser is capable of parsing the input-sentence and whether the sentence is grammatical. Both checks are required for the creation of exercises.

Stories can also be entered after the parser has been cancelled. In such cases the only type of operation to be carried out is the connection of each word to its first dictionary meaning. The advantages of this option are that the input process is faster and that texts of any degree of difficulty can be entered. This kind of text can only be used for receptive exercises.

The generative potential of the parser and the great amount of information in the lexical database make it possible for the program to adjust quickly to different teaching methods by allowing for the addition of method-specific texts. The menu-driven environment and the extensive contextsensitive help-options make the program very user-friendly for both teachers and learners. The unambiguous screen layout makes it relatively simple to enter commands. It should be borne in mind, however, that the program's full potential can only be realized with suitable machines (i.e. computers with 80386 processors, $25 \mathrm{MHz}, 4 \mathrm{Mb}$ RAM hard disk, Windows 386, Prolog 2, CD-ROM XA). 
THE RESEARCH

The research setup

Our research addressed the following questions:

(1) How do learners use the different options offered by the program?

(2) What is their appreciation of the program as users?

(3) What are the learning results of the program?

With regard to the first question, the investigation had to establish the frequency of use of the available options for each of the different types of exercises. Frequency of use may be regarded as an indiction of the value that the user attaches to a certain option. The frequency indication is supplemented with an explicit assessment by learners of the program as regards its presentability, usefulness, accessibility and perceived value. The learners' assessments were measured four times by means of a short questionnaire. The learning results of IT'S ENGLISH were measured along two parameters. The first of these concerned the knowledge and productive use of newly-acquircd English words. The second concerned the learners' skills in deducing the meanings of English words from their contexts. To provide answers to the research questions, data were collected through the creation of an experimental teaching-learning setup, in which parts of the 'regular' teaching of English were replaced by IT'S ENGLISH as a teaching-aid. In particular those parts of the teaching were involved which concentrated on the learning of new English vocabulary items.

\section{Subjects}

The teaching experiment involved the third grades (age 15 years) the two participating secondary schools. For technical and administrative reasons it was necessary to restrict the number of participating pupils. The two participating schools, both broad-based institutions for secondary education, were approached through their English departments. One school was selected for its use of Notting Hill Gate, the other school for its use of Mainstream. The other selection criterion was the availability of computer-rooms with at least eight separate personal computers for the experimental teaching-learning environment.

At each of the schools pupils from one HAVO-class, the middle form of secondary education, and one VWO-class, the highest form of secondary education, took part in the experiment; eight pupils per class, yielding a total of 32 subjects. The four groups were matched by means of pretests with the control groups (four sets of eight pupils from the remaining four classes).

\section{Procedure}

During a period of 8 weeks, $1 \mathrm{~h}$ per week was devoted to its IT'S ENGLISH exercises by the pupils who participated in the research. The first six sessions started with the reading of a text, followed by the completion of a cloze-text. During the first three sessions the cloze-text was created by the learners themselves on the basis of an oral assignment given by the researcher/teacher. It was then completed. During the following three sessions the cloze-exercise was prepared by the researcher/teacher. For the remaining two computer-aided sessions the order was reversed. The completion of the cloze-exercise came first, after which, if time allowed, the accompanying text or another text was read.

The pupils from the control group, who did not take part in the experimental computer-aided lessons, followed the normal lessons given by their own teacher. These normal lessons took place concurrently with the experimental lessons. They dealt with the same content, and thus presented the same words, as the computer-aided lessons.

\section{Tests}

The data about program use were obtained from individual log files in which every action of each pupil-user was recorded. Every other week a short questionnaire was completed in which each pupil was asked for his or her opinion about certain user aspects of the program. This questionaire consisted of 13 questions. Pupils were requested to rate aspects of the program on a five-point scale, from very easy to very difficult. 
To measure the learning results, the following three pairs of parallel tests were created: the first test for knowledge of the lexical items presented in the program (20 items); the second test being productive/reproductive (a cloze-text with 10 blanks and a list of 10 words, each to be used in a correct English sentence); the third test, a distractor test consisting of 20 underlined, almost certainly unknown words, whose meaning was to be deduced from the context. One of each tests was used as a pretest and one as a posttest. The knowledge-test and the production tests were method-specific.

\section{RESULTS}

\section{User aspects}

The first research question concerns the frequency with which pupils used information about English words which, thanks to being able to use CD-ROM, were available in IT'S ENGLISH. With the aid of straight counts it was established how often pupils doing the exercises used certain kinds of information about English words. The frequency counts took place in the four lessons during the last 4 weeks of the experiment. Data from the first 4 weeks were left out of consideration, among other reasons because of run-in problems with the program and hardware-configurations in the network.

\section{Receptive exercises}

The uses of information about English words were recordcd scparately for the reading exercises and the cloze-exercises. The use of reading exercises, much more than is the case in the cloze-exercises, is explorative in character. The use of options in the cloze-exercises is more often governed by the omitted words and by those to be filled in. In the last 4 weeks of the experiment 48 reading exercises were completed ( 22 exercises by 16 Mainstream pupils and 26 exercises by 16 Notting Hill Gate pupils), during which information about English words was called up in one form or another, in total 469 times. This amounts to an average of 9.8 times per exercise. There is a remarkable difference between Mainstream pupils and Notting Hill Gate pupils in this regard: 7.2 as against 12 times, respectively.

\section{Cloze exercises}

A cloze-exercise consists of a text-sentence from which certain words have been omitted. The learner has to fill in the correct word by using the context in which the omitted word occurs. In the cloze-exercises presented to the pupils during the experiment the words omitted were marked as new in the relevant lessons.

During the 4 weeks of the experiment a total of 1987 words were filled in by the pupils. A total of $928(=47 \%)$ of these were correct first time. In filling in the other 1050 words the pupils called up different forms of information available from the program about the omitted words. In slightly more than half of the cases pupils were able to fill in the correct word only if they used the information available from the program. In the course of the experiment the order of the reading-exercise and the cloze-exercise was reversed. In Weeks 5 and 6 lessons started off with a reading-exercise, followed by a cloze-exercise over the same text. In Weeks 7 and 8 pupils started with the cloze-exercise. This change was decided upon in order to study the use of the help options provided by the program under conditions in which the pupils, while doing cloze-exercises, could not rely on their recall of words from the reading text.

The results show that in Weeks 5 and 6 pupils filled in $46 \%$ of the omitted words correctly first time, leaving them to call up additional information in $54 \%$ of the remaining correct completions. In Weeks 7 and $8,50 \%$ of the omitted words were filled in correctly first time, leaving an equal percentage for extra information. The amount of extra information in weeks 7 and 8 is smaller than in weeks 5 and 6 . It is possible that a difference in degree of difficulty played a role in this. For the 1050 cascs in which a word was correctly filled in after extra information, information in some form or another was requested a total of 1740 times. This amounts to an average of 1.7 times per omitted word. 


\section{Types of exercises compared}

For the reading exercises call-ups of meaning definitions are predominant. These constitute nearly half of all the cases of requested information. This type of information does seem the most relevant in the reading of a text. Unfamiliarity with a word during reading naturally leads to a search for the meaning of that word. For that reason context sentences, which can also provide relevant information about the meaning of a word, occupy second place in the pupils' preferences for types of information. The other types are hardly used at all (perhaps sometimes out of curiosity). This is also quite understandable. Synonyms, antonyms, superordinates, information about word-class, and morphological forms do not form obvious sources of information in the search for word-meaning during reading. What is striking is the frequency with which information about the pronunciation of words is called up during reading. In part this might be explained by the novelty of this option and the pupils' natural curiosity.

We conclude that the pupils use the available types of information in an adequate and goal-oriented way during the reading of the English texts. They chose those types of information that are most relevant to their goal, which is understanding the English text.

In the cloze-exercises half of the requested information consisted of context sentences (in which, as may be recalled, the omitted cloze-text word is also omitted). This, too, signals a relevant preference. For it allows the omitted word to be placed in several contexts apart from its context in the exercise. Another recurring solution to the problem of filling in the blanks is deducing an omitted word from its available meaning definition. One-third of all the information requested during cloze-exercises consists of meaning definitions. The other types of information are hardly used, with the exception of synonyms, which constitute $5 \%$ of all requested information. This is also a relevant choice: when one knows a synonym a word is easier to find.

Again the conclusion is warranted that pupils use the available information adequately and consciously and that they select those types of information that lead the most directly to the identification of a word.

This conscious, goal-oriented selection of types of information may be further illustrated with a comparison between the types of information used in two different exercises, namely, reading and filling in words. Figure 1 shows a comparison between the two types of exercises and the use of the help-facility.

The differences in preference between reading- and cloze-exercises is clear. The relevance of these preferences has already been discussed. The pupils' choice of different types of information for different exercises again confirms the conclusion that the pupils working with IT'S ENGLISH handle the information about words that is available from the program in an adequate, goal-oriented way.

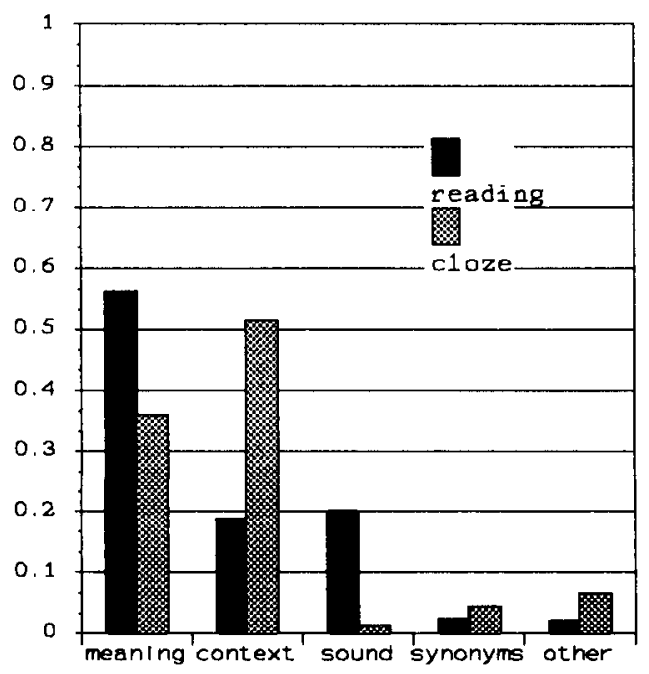

Fig. 1. Comparison of reading and cloze tests in pupils' use of additional information. 


\section{Program users' assessments}

The assessment-scores for all kinds of user-aspects of the program, as well as its educational effectiveness, were mildly positive on a scale (between 2 and 3 on a 5-point scale; 1 is positive and 5 is negative). The only aspect that showed a mildly negative score (between 3 and 4 ) involved the speed of the program. Working with a network of XT-computers involves insufficient speed for a number of actions. Reaction-times exceeding $2 \mathrm{~s}$ quickly tend to become irritating. As was mentioned before, the use of the complete program is only optimal with advanced personal computers.

\section{The learning results}

Since the texts and two of the three tests for the participating schools are different, the results for the two schools were analyzed separately. The effects of the program were determined in a number of multivariate covariance analyses with the relevant pretests as covariables. In the production tests no significant differences were found between the experimental and the control groups.

By contrast (see Table 1), knowledge of vocabulary turns out to be significantly higher for the experimental Notting Hill Gate group than for the control group, with the pretest as covariable. It is interesting to know in this respect that the pupils in question used the help-options relatively often. Significant differences between the mean scores on the test to deduce the meaning of English words were only found between the HAVO and VWO pupils, with the latter showing higher scores (Table 2).

Table 1. Means and standard deviations of test "Knowledge of Vocabulary"

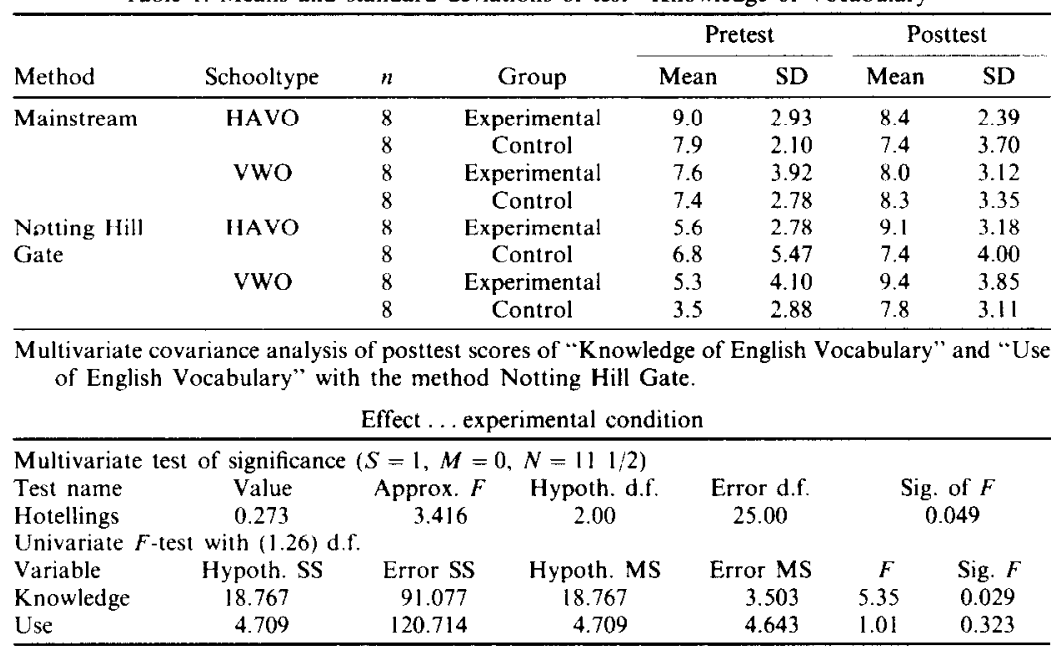

Table 2. Means and standard deviations of the scores of the test "Deduction of meaning of English words"

\begin{tabular}{|c|c|c|c|c|c|c|c|}
\hline \multirow[b]{2}{*}{ Method } & \multirow[b]{2}{*}{ Schooltype } & \multirow[b]{2}{*}{$n$} & \multirow[b]{2}{*}{ Group } & \multicolumn{2}{|c|}{ AFL-I } & \multicolumn{2}{|c|}{ AFL-II } \\
\hline & & & & Mean & $\mathrm{SD}$ & Mean & $\mathrm{SD}$ \\
\hline \multirow[t]{4}{*}{ Mainstream } & HAVO & 8 & Experimental & 3.0 & 2.56 & 9.0 & 2.27 \\
\hline & & 8 & Control & 2.6 & 2.83 & 7.1 & 3.23 \\
\hline & Vwo & 8 & Experimental & 4.0 & 2.98 & 11.8 & 3.11 \\
\hline & & 8 & Control & 3.6 & 3.29 & 10.3 & 4.75 \\
\hline Notting Hill & HAVO & 8 & Experimental & 2.6 & 3.70 & 7.6 & 3.42 \\
\hline \multirow[t]{3}{*}{ Gate } & & 8 & Control & 4.6 & 4.93 & 8.4 & 3.96 \\
\hline & vwo & 8 & Experimental & 3.0 & 3.02 & 9.0 & 4.24 \\
\hline & & 8 & Control & 2.3 & 2.71 & 7.8 & 4.86 \\
\hline
\end{tabular}

Analysis of the scores on test "Deduction of meaning of English words"-II.

Analyses of variance

\begin{tabular}{lrrrrc}
\hline Source of variation & SS & d.f. & MS & $F$ & $P$ \\
Covariates & 336.144 & 1 & 336.144 & 36.420 & 0.000 \\
AFL-I & 336.144 & 1 & 336.144 & 36.420 & 0.000 \\
Main effects & 82.419 & 3 & 27.473 & 2.977 & 0.040 \\
Exp. condition & 18.844 & 1 & 18.844 & 2.042 & 0.159 \\
Schooltype & 41.271 & 1 & 41.271 & 4.471 & 0.039 \\
Method eng. & 21.638 & 1 & 21.638 & 2.344 & 0.132 \\
\hline
\end{tabular}


Since there was prior control for differences in word-deduction skills this result means that this particular skill improved more for VWO pupils during the 8 weeks of the experiment than for HAVO pupils.

\section{CONCLUSIONS}

The help-options offered by the program appear to have been used selectively by the pupils. In reading texts with new words they more often use the meaning definition of the new word, whereas in completing fill-in texts they more often try to find the correct word by calling up context sentences in which the same word (again in its blank form) occurs in an everyday English context. This confirms our idea that learning words from contexts is a suitable method for more productive exercises. Markham[5] also carried out research into the teaching of words in a computer-aided environment by means of presenting meaning definitions as against presenting words in context. His conclusion is that "Although definitional knowledge appears to be important in developing a basic concept of a word in the initial phases of vocabulary development, long-term, depthoriented gains may be more closely associated with exposure to words embedded in a variety of natural paragraphs". It still has to be shown that the acquired words can subsequently be used with greater facility in free writing. Some evidence for this can be found in van der Gein's research [6]. This shows that a sentence-building course, which required practicing with sentence patterns in order to gain insight into the relationship between the structural form of patterns and their meanings, had a positive effect on writing proficiency.

The hardware-configurations with which this research was carried out did not allow the investigation free text-production by computer. However, first results [3] indicate that pupils who worked with the more communicative methods discussed here made greater progress in vocabulary acquisition than those who were taught in the more traditional context of the control group.

\section{REFERENCES}

1. Kanselaar $G$. and van Maanen T., Vreemde-talenonderwijs met computers in het voortgezet onderwijs: verkenning en inventarisatie van een onderzoeksgebied. In Cluster $V$ onderwijsonderzoek: twee studies van het Instituut voor het onderzoek van het onderwijs. PSOI-reeks No. 31, pp. 3- 154 (1987).

2. Sinclair J. (Ed.), Collins COBUILD English Language Dictionary. Collins, London (1987).

3. Kanselaar G., Giezeman M., Jaspers J., Koster L., van der Veen J., Wichmann H. and Zuidema J., Computerondersteund vreemde talenonderwijs (eindverslag van SVO-project 7108). ISOR. Rijksuniversiteit te Utrechi (1989).

4. Neuner G., Krüger M. and Grewer U., Ubungstypologie zum kommunikativen Deutschunterricht. Langenscheidt KG, Berlin (1981).

5. Markham P., Effects of contextual versus definitional computer-assisted vocabulary instruction on immediate and long-term vocabulary retention of advanced ESL students. Educl Psychol. 9, 121-126 (1989).

6. van de Gein J., The Sense of Sentences. A Study into the Effects of Grammar Instruction upon Junior Writing. Proefschrift, Utrecht (17 May 1991).

\footnotetext{
APPENDIX

Recent Developments

In order to remove memory limitations and improve on the user-interface a new version of the program has been developed. The new version runs under Microsoft-Windows version 3.1 in enhanced mode. This version was implemented in Prolog-2 for Windows, with some extensions in TurboPascal for windows.

The CDROM-XA standard failed in becoming a standard for multimedia applications. The hardware (i.e, the CD-ROM with interface board) is relatively expensive. Therefore we intend to convert the audio component of the program to conform with the Multimedia-PC standard. This will enable the use of readily available hardware (e.g. SoundBlaster Multimedia upgrade kit).

In the NESA-program we are cooperating with universities in Hungary (Budapest, Szeged and Pecs), Czech Republic (Prague), Slowakya (Bratislava) and Poland (Warsaw). Research is being carried out into the effects of the program on learning English as a foreign language. The research also involves evaluating exercises and developing new types of exercises.
} 